\title{
Enhanced Sensitivity of the MRL/MpJ Mouse to the Neuroplastic and Behavioral Effects of Acute and Chronic Antidepressant \\ Treatments
}

\author{
Darrick T. Balu ${ }^{1,2}$ \\ ${ }^{1}$ Department of Psychiatry, Harvard Medical School, Belmont, MA, USA \\ ${ }^{2}$ Laboratory for Psychiatric and Molecular Neuroscience, McLean Hospital, Belmont, MA, USA
}

\begin{abstract}
Adult hippocampal neurogenesis has been implicated in the pathophysiology of depression and in the therapeutic effects of antidepressant drugs. Current immunohistochemical methods that study neurogenesis are time consuming and labor intensive. Therefore, a significantly more rapid flow cytometric method was characterized to measure neurogenesis in the adult mouse brain. The sensitivity of mice to the effects of antidepressant treatments is dependent on genetic background. Thus, studies were conducted comparing the responsiveness of two inbred mouse strains, MRL/MpJ and $\mathrm{C} 57 \mathrm{BL} / 6 \mathrm{~J}$, to the acute and chronic effects of antidepressants on neurochemistry and behavior. Acutely, MRL/MpJ mice displayed more robust behavioral and neurochemical responses to pharmacologically distinct antidepressants than C57BL/6J. Chronic administration of the antidepressant drugs fluoxetine and desipramine produced robust elevations in hippocampal cell proliferation and brain derived neurotrophic factor (BDNF) protein levels in MRL/MpJ mice. C57BL/6J mice treated similarly with antidepressant drugs were mainly unresponsive on these measures. Animals were tested in the novelty-induced hypophagia (NIH) paradigm to examine a behavioral response associated with chronic, but not acute, antidepressant treatment. Only MRL/MpJ mice were behaviorally responsive to chronic antidepressant administration in the NIH paradigm. The positive effects of chronic antidepressants on hippocampal cell proliferation and BDNF paralleled the ability of these drugs to produce changes in NIH behavior. These studies highlight the advantages of utilizing flow cytometry to study hippocampal neurogenesis and identify the MRL/ $\mathrm{MpJ}$ mouse as a strain with superior response to antidepressant drug treatments that may lead to a better understanding of the genetics behind antidepressant efficacy and sensitivity.
\end{abstract}

\section{Keywords}

neurogenesis; flow cytometry; antidepressants; brain derived neurotrophic factor (BDNF); noveltyinduced hypophagia $(\mathrm{NIH})$

\section{Analysis of Adult Hippocampal Neurogenesis Using Flow Cytometry}

The persistence of brain neurogenesis throughout the life span in different species of animals, from birds to primates (Gould, 2007), and now even humans (Manganas et al., 2007), has been well established. In mammals, the only brain regions established to support neurogenesis are the subventricular zone (SVZ), projecting a chain of neurons to the olfactory bulb, and the

Corresponding author: Darrick T. Balu, Ph.D., Harvard Medical School, Department of Psychiatry, McLean Hospital MRC 114, Belmont, MA 02478, Tel.: + 1617855 2031, Fax: + 1617855 2705, dbalu@ @clean.harvard.edu. 
subgranular zone (SGZ) of the hippocampus, generating neurons that migrate within the granule cell layer (GCL). Neurogenesis is a general term that defines a complex process of cell generation, including proliferation of multipotent stem cells, differentiation into distinct neuronal subtypes, and survival of neurons for incorporation into cellular networks (Ehninger $\&$ Kempermann, 2008). These neurogenic zones are differentially regulated and are modulated by specific neurotransmitter systems, growth factors, endogenous psychotropic systems, sex hormones, stress, exercise, and others. (Balu \& Lucki, 2009; Zhao, Deng, \& Gage, 2008).

Various functions have been proposed for neurogenesis in different brain regions. The most generally significant role of hippocampal neurogenesis, though, may be its participation in particular psychiatric and neurodegenerative diseases. Adult hippocampal neurogenesis has been implicated in the etiology of depression, as well as in the therapeutic actions of antidepressant treatments (Dranovsky \& Hen, 2006).

The association between neurogenesis and depression has sparked interest in developing this process as a target for therapeutic intervention. In the brain, neurogenesis is commonly quantified by administration of 5-bromo-deoxyuridine ( $\mathrm{BrdU})$, a thymidine analog that is taken up by actively dividing cells. Following subsequent sacrifice, perfusion, and brain sectioning, $\mathrm{BrdU}$ is detected following immunohistochemical development of the tissue and the number of BrdU-positive cells are counted under a microscope (Dolbeare, 1996; Gratzner, 1982). However, this technique is quite slow and manpower intensive, a pharmacological study could take months for analysis. Moreover, subjective application of criteria for cell counting may vary between individuals requiring the same person to complete an entire experiment and making replication between laboratories more difficult. These aggregate technical restrictions have delayed and limited the development of neurogenesis for a number of neurobiological applications, especially for processes such as drug discovery.

A flow cytometric method was developed to measure BrdU incorporation rapidly and objectively in brain tissue, with most studies able to be completed within a single day (Balu, Hodes, Hill et al., 2009). Experiments were carried out to validate flow cytometry assay and to expand on a previously reported study using this technique (Bilsland et al., 2006). The initial validation studies compared multiple BrdU dosing and loading protocols to optimize the dosing strategy in mice that produced the best signal to noise ratio. Secondly, BrdU incorporation was examined in different brain regions to establish the relative range of BrdU incorporation. One area known to have a high level of proliferative activity is the SVZ. Flow cytometry demonstrated that cell proliferation in the SVZ was 7-fold higher than in the hippocampus, which is in agreement with a comparison of these regions reported using immunohistochemistry (Kim et al., 2006). BrdU incorporation was also detected in the cerebellum and the amygdala, though lower in comparison to the hippocampus. Third, flow cytometry was used to assess whether the survival of adult born hippocampal progenitors could be followed for weeks after labeling with BrdU. At 7 and 21 days after the last BrdU injection, $55 \%$ and $65 \%$, respectively, fewer BrdU positive cells were measured. This rapid decay function is in agreement with what has been reported for hippocampal cell survival using immunohistochemistry in the mouse (Navailles, Hof, \& Schmauss, 2008).

In order to further validate the use of flow cytometry, changes in cell proliferation were examined after 3 kinds of manipulations that have been shown to regulate neurogenesis and compared with the values reported using immunohistochemistry. Streptozotocin (STZ), which destroys the insulin producing cells of the pancreas, was used to induce experimental type-1 diabetes. Six weeks after the induction of diabetes, hippocampal cell proliferation was reduced by $25 \%$, consistent with what has been reported using immunohistochemistry (Beauquis, Roig, Homo-Delarche, De Nicola, \& Saravia, 2006). Administration of the toxin $N$-Ethyl- $N$-(2chloroethyl)-2-bromobenzylamine hydrochloride (DSP-4), destroys noradrenergic cell bodies 
in the locus coeruleus, and was used to deplete norepinephrine in the hippocampus and remaining forebrain. Eight days after depletion, cell proliferation in the hippocampus was decreased by $30 \%$. Again, this value is in agreement with what was reported using conventional methods (Kulkarni, Jha, \& Vaidya, 2002). Chronic administration of somatic and pharmacologic antidepressant treatments increases hippocampal neurogenesis (Dranovsky \& Hen, 2006). As measured with flow cytometry, chronic administration (5 days) of electroconvulsive shock (ECS), a somatic treatment for depression, as well as chronic treatment (21 days) with the antidepressant fluoxetine elevated hippocampal cell proliferation. This increase in cell proliferation with fluoxetine was detected as early as 14 days, but not at 7 days, into treatment. Finally, measures of cell proliferation obtained by immunohistochemical and flow cytometric methods after chronic administration of fluoxetine were compared directly within the same animals by bisecting the brain prior to processing. The results obtained with both methods were convergent and significantly correlated to each other.

\section{Strain Differences in Response to Antidepressant Treatments}

The purpose of the following studies was to examine the behavioral and neurochemical responses of a special mouse strain, the MRL/MpJ strain, to acute and chronic antidepressant treatments. The MRL/MpJ mouse strain was selected because of its enhanced healing and regenerative response to injury (Clark, Clark, \& Heber-Katz, 1998). The process of healing from an ear punch is faster and more complete in MRL/MpJ mice; at 15 days post-injury, MRL/ $\mathrm{MpJ}$ mice show 85\% reduction in ear hole size while C57BL/6 mice (controls) show a maximal closure of only $30 \%$. Enhanced healing of cardiac wounds has also been reported in MRL/MpJ mice, similar to that seen in non-mammalian tissue regeneration (Leferovich et al., 2001). Moreover, this increase in cell proliferative capacity was found to extend into the central nervous system (Baker et al., 2006).

There is also a substrain of MRL/MpJ, MRL-Fas ${ }^{l p r}$, which is homozygous for the lymphoproliferation spontaneous mutation (Fas ${ }^{l p r}$ ) and develops a lupus-like autoimmune disease starting at about three months of age (Hewicker 1990). As compared to MRL-Fas $p r$ mice, MRL/MpJ mice displayed less anxiety and depressive-like behaviors (Gao et al., 2009; Sakic, Szechtman, \& Denburg, 1997). However, the MRL/MpJ mice were not compared with any strains ordinarily used in psychopharmacology investigations.

We therefore chose to compare the antidepressant responses of the MRL/MpJ mice with those of $\mathrm{C} 57 \mathrm{BL} / 6 \mathrm{~J}$ mice for several reasons. $\mathrm{C} 57 \mathrm{BL} / 6 \mathrm{~J}$ was the control strain used in the wound healing and regeneration studies and constitutes a portion of the MRL/MpJ genetic background. In addition, C57BL/6J mice are used commonly in behavioral and pharmacological studies. We examined the baseline neurochemistry of MRL/MpJ mice, as well as their behavioral and neurochemical responses to acute and chronic antidepressant treatments in comparison with ordinary $\mathrm{C} 57 \mathrm{BL} / 6 \mathrm{~J}$ mice.

\section{Neurochemical Differences between Mouse Strains}

The primary effect of the most currently available pharmacologic antidepressants is to enhance the transmission of brain monoamine systems, principally the neurotransmitters serotonin (5HT) and norepinephrine (Frazer, 2001). Therefore, tissue content levels of these molecules were compared between strains in brain regions that are implicated in the etiology of depression. MRL/MpJ mice had significantly higher tissue levels of serotonin than C57BL/6J mice in the hippocampus, frontal cortex, amygdala, and brain stem. MRL/MpJ mice also had significantly higher levels of the major serotonin metabolite, 5-hyrdroxy-indole acetic acid (5HIAA), than C57BL/6J mice in the frontal, amygdala, and brain stem. The ratio of 5-HT/5HIAA, which is used an index of 5-HT turnover, was significantly different between the two strains only in the frontal cortex. 
Microdialysis was used to measure extracellular levels of 5-HT in the hippocampus and to follow the response to an acute challenge with citalopram. At baseline, there was no difference in the dialysate levels of 5-HT between strains. An acute injection of citalopram $(20 \mathrm{mg} / \mathrm{kg})$ robustly increased the release of 5-HT in the ventral hippocampus of both mouse strains. However, the MRL/MpJ mice showed a significantly greater response to citalopram, increasing 5-HT levels 7-9 times higher than baseline. The increase of hippocampal 5-HT in C57BL/6J mice was more modest, 3-4 times higher than baseline at peak response. This difference between groups persisted throughout the course of sampling (160 min).

\section{Strain Sensitivity to the Acute Effects of Antidepressant Treatments}

Various behavioral tests in rodents are used to evaluate compounds for potential antidepressant activity (Crowley \& Lucki, 2005). One such paradigm is the tail suspension test (TST). In this paradigm (Steru, Chermat, Thierry, \& Simon, 1985), mice are suspended by their tail from an elevated bar for several minutes. Usually, the mice engage in escape-oriented behaviors, such as body jerks and leg kicks, followed temporally by increasing bouts of immobility. The amount of time that the mouse spends immobile is decreased by antidepressant treatment. The TST has been shown to be sensitive to numerous antidepressants from various different pharmacological classes (Perrault, Morel, Zivkovic, \& Sanger, 1992; Steru et al., 1987; Steru et al., 1985; Teste, Martin, \& Rinjard, 1990) and therefore has good predictive validity. Locomotor activity is often tested to distinguish antidepressant activity from general psychostimulants, since most antidepressants reduce immobility even though they suppress locomotor activity of rodents under nonstressful conditions (Crowley \& Lucki, 2005).

Different inbred and outbred mouse strains show performance differences on various tests measuring stress-induced behavioral despair, including the TST (Crowley \& Lucki, 2005). There are also mouse strains that demonstrate divergent responses to different types of antidepressant drugs in the TST (Cryan, Mombereau, \& Vassout, 2005). Several studies have surveyed mouse strains for differences in baseline immobility and antidepressant sensitivity in this paradigm (Crowley, Blendy, \& Lucki, 2005; Liu \& Gershenfeld, 2001; Ripoll, David, Dailly, Hascoet, \& Bourin, 2003).

Therefore, the MRL/MpJ and C57BL/6J strains were first compared for their acute behavioral responsiveness to antidepressant treatments by measuring the effects of the selective serotonin reuptake inhibitor (SSRI), citalopram $(10,20 \mathrm{mg} / \mathrm{kg}$ ), and the tricyclic antidepressant, desipramine $(10,20 \mathrm{mg} / \mathrm{kg}$ ), in the TST. At baseline, MRL/MpJ mice had a lower level of immobility than the C57BL/6J mice. However, the response (reduction of immobility) of MRL/ $\mathrm{MpJ}$ mice to citalopram was 3-4 times greater than that observed in C57BL/6J mice. A similar pattern of results in the TST between these two strains was observed following an acute desipramine challenge. MRL/MpJ mice had a 2-3 fold larger response than C57BL/6J mice.

Baseline locomotor activity did not differ between the two strains of mice. Citalopram produced elevations of locomotor activity in both strains of mice, though to a greater extent in C57BL/ $6 \mathrm{~J}$ mice. The increased locomotor effects of citalopram agree with previously published studies (Brocco, Dekeyne, Veiga, Girardon, \& Millan, 2002; Crowley et al., 2005). Contrary to the effects of citalopram, desipramine caused a reduction in locomotor activity in both strains that was slightly more robust in the C57BL/6J. The reductions of immobility in the TST and locomotive alterations in response to antidepressant treatments did not mirror each other in the two strains. These data suggest that the antidepressant-like effects of citalopram and desipramine in the TST are not correlated with changes in locomotor activity. 


\section{Neuroplastic Changes Associated with Chronic Antidepressant Treatments}

One of the major clinical limitations of current pharmacologic antidepressant therapies is that 2-6 weeks of treatment is usually necessary before therapeutic effects develop, even though monoaminergic signaling is altered shortly after the beginning of treatment. The temporal onset of clinical antidepressant effects has led to the hypothesis that the underlying mechanisms responsible for the therapeutic effects of chronic antidepressant drug administration arise, in part, from molecular and cellular adaptations that require persistent drug exposure. One such neurochemical change includes upregulation of hippocampal neurogenesis (Dranovsky \& Hen, 2006). Another adaptation is the increase of neurotrophins, most notably brain derived neurotrophic factor (BDNF) (Duman \& Monteggia, 2006), which are important for neuronal survival and differentiation, as well as other types of synaptic plasticity, including long-term potentiation (LTP) (Figurov, Pozzo-Miller, Olafsson, Wang, \& Lu, 1996) and activitydependent dendritic development (Greer \& Greenberg, 2008).

Studies of chronic antidepressant treatments in mice are important because of their reduced costs, relative to rats, and because of the variations in response occurring from natural variability between strains or targeted genetic modifications. However, chronic antidepressants have produced inconsistent results in different mouse strains with regard to hippocampal neurogenesis (Gur et al., 2007; Holick, Lee, Hen, \& Dulawa, 2007; Lagace, Fischer, \& Eisch, 2007; Miller, Schultz, Gulati, Cameron, \& Pletcher, 2008; Navailles et al., 2008; Santarelli et al., 2003). Chronic, but not acute, treatment with tricyclic antidepressants elevated BDNF mRNA in the mouse (Conti, Cryan, Dalvi, Lucki, \& Blendy, 2002; Tsankova et al., 2006). However, few studies have examined the effects of chronic antidepressant treatments on BDNF protein levels in the murine brain. Owing to the uncertainty of the effects of chronic antidepressant drug treatments in mice, we compared the sensitivity of MRL/MpJ and C57BL/ $6 \mathrm{~J}$ mice to the neurogenic and neurotrophin enhancing properties of chronic antidepressant treatments, by administering two pharmacologically distinct antidepressants, the SSRI, fluoxetine and desipramine (Balu, Hodes, Anderson, \& Lucki, 2009). Flow cytometry was utilized to assess the effects of antidepressants on cell proliferation and survival of adult-born hippocampal progenitors, while BDNF protein levels in brain regions associated with depression were quantified using enzyme-linked immunosorbent assay (ELISA).

Hippocampal cell proliferation was increased significantly, and dose-dependently, after chronic administration of fluoxetine $(5,10 \mathrm{mg} / \mathrm{kg})$ or desipramine $(5,10 \mathrm{mg} / \mathrm{kg})$ for 21 days in MRL/MpJ mice. The lowest dose $(2.5 \mathrm{mg} / \mathrm{kg})$ of fluoxetine or DMI failed to elevate cell proliferation. A peak 3-fold elevation of proliferative activity was achieved with the $5 \mathrm{mg} / \mathrm{kg}$ dose of fluoxetine, whereas the highest dose tested $(10 \mathrm{mg} / \mathrm{kg})$ produced a 2 -fold increase. The peak effect for desipramine, a 2-fold elevation of proliferation, was achieved with the $5 \mathrm{mg}$ / $\mathrm{kg}$ dose, whereas the highest tested dose $(10 \mathrm{mg} / \mathrm{kg})$ produced a $50 \%$ increase. Contrary to the results obtained with MRL/MpJ mice, chronic treatment of C57BL/6J mice with fluoxetine or desipramine, at any of the tested doses, failed to increase hippocampal cell proliferation.

The ability of chronic antidepressants to regulate the survival of adult-born hippocampal progenitors was also compared between strains. For these experiments, only the $5 \mathrm{mg} / \mathrm{kg}$ dose of fluoxetine and desipramine, which produced the peak effects on cell proliferation, were tested. Neither fluoxetine nor desipramine altered the survival of these cells in either the MRL/ $\mathrm{MpJ}$ strain or the $\mathrm{C} 57 \mathrm{BL} / 6 \mathrm{~J}$ strain.

Chronic treatment of MRL/MPJ mice with fluoxetine elevated BDNF protein levels in several brain regions. In the hippocampus, both the 5 and $10 \mathrm{mg} / \mathrm{kg}$ doses significantly increased BDNF protein levels by 2 -fold. In the frontal cortex, the lower dose of fluoxetine elevated BDNF levels by $20 \%$, whereas the higher dose caused a significant 3-fold elevation in BDNF protein. Fluoxetine at $10 \mathrm{mg} / \mathrm{kg}$ also increased BDNF levels in the amygdala by 3 -fold. Chronic 
treatment of MRL/MpJ mice with 5 and $10 \mathrm{mg} / \mathrm{kg}$ of DMI significantly elevated BDNF protein levels in the frontal cortex by $15 \%$, without effect in any of the other examined brain regions. Chronic treatment of C57BL/6J mice with fluoxetine or desipramine produced different effects on BDNF protein. Fluoxetine $(10 \mathrm{mg} / \mathrm{kg})$ caused an almost two-fold elevation of BDNF levels in the amygdala, whereas BDNF levels were reduced by $30 \%$ in the hippocampus. Fluoxetine at $5 \mathrm{mg} / \mathrm{kg}$ did not affect BDNF levels in any of the examined brain regions. In contrast to the results with MRL/MpJ mice, chronic treatment of C57BL/6J mice with desipramine $(5,10 \mathrm{mg} /$ $\mathrm{kg}$ ) did not increase BDNF protein levels in any region of the forebrain, but selectively reduced BDNF levels by $50 \%$ in the brainstem.

\section{Effects of Chronic Antidepressant Treatments on Novelty-Induced Hypophagia Behavior}

There are few behavioral tests in rodents that are responsive only after the chronic administration of antidepressant drugs. Behavioral hyponeophagia paradigms that measure reduction of the consumption of a palatable food by exposure to a novel environment have been shown to respond to antidepressant treatments only after chronic administration (Bechtholt, Valentino, \& Lucki, 2008; Dulawa \& Hen, 2005). Novelty-induced hypophagia $(\mathrm{NIH})$, which does not require food deprivation, is sensitive to chronic antidepressant treatments in a number of mouse strains (Gur et al., 2007; Merali, Levac, \& Anisman, 2003). The behavioral effects of chronic antidepressants in novelty suppression of feeding, a version of the hyponeophagia test requiring food deprivation, are related to their ability to enhance hippocampal neurogenesis (Jiang et al., 2005; Santarelli et al., 2003).

The exposure of MRL/MpJ mice to a novel environment increased their latency to consume food 6-fold, compared with their home cage latency times. Chronic treatment of these mice with fluoxetine $(5 \mathrm{mg} / \mathrm{kg})$ or desipramine $(5 \mathrm{mg} / \mathrm{kg})$ significantly reduced the consumption latencies by $70 \%$ and $85 \%$, respectively. Exposure to the novel environment produced an increase in approach latency in the C57BL/6J mice to a greater extent than $\mathrm{MRL} / \mathrm{MpJ}$ mice. But unlike in MRL/MpJ mice, chronic antidepressant drug treatments did not reduce their latency to eat in the novel environment.

\section{Conclusions}

The first set of experiments validated the utility of flow cytometry in analyzing in vivo adult hippocampal cell proliferation and survival from murine brain tissue in a reliable and expeditious fashion. The inherent speed of the flow cytometry technique makes it an attractive method by which neurogenesis can be utilized as a platform for novel drug discovery and other purposes requiring high throughput. Moreover, it has the potential to greatly advance the neuroscience community's understanding of the biological underpinnings of adult neurogenesis.

The second group of experiments showed differences between two mouse strains, MRL/MpJ and $\mathrm{C} 57 \mathrm{BL} / 6 \mathrm{~J}$, in baseline neurochemistry as well as antidepressant-induced neurochemical and behavioral responsiveness. MRL/MpJ mice had higher tissue levels of 5-HT than C57BL/ $6 \mathrm{~J}$ mice in several brain regions associated with depression (Table 1; insert here). Moreover, $\mathrm{MRL} / \mathrm{MpJ}$ mice had 2-fold higher levels of 5-HT release in the hippocampus following citalopram administration than C57BL/6J mice. This increased level of neurotransmitter content and release in MRL/MpJ mice was associated with a much more robust behavioral profile to the acute effects of pharmacologically distinct antidepressants in the TST (Table 2; insert here). These data suggest that the MRL/MpJ strain is an excellent candidate for screening novel compounds with potential acute antidepressant activity, especially those with mechanisms involving serotonergic and/or noradrenergic signaling. 
The final set of studies also demonstrated the existence of important strain differences in the responses of mice to chronic administration of antidepressant drugs. MRL/MpJ mice, known distinctively for enhanced wound healing and tissue regeneration (Clark et al., 1998; Leferovich et al., 2001) appear also to demonstrate exaggerated neuroplastic responses. The robust increases in hippocampal cell proliferation, measured using the developed flow cytometry method, and cortico-limbic BDNF protein levels paralleled the ability of these drugs to produce changes in NIH behavior in MRL/MpJ mice. In contrast, $\mathrm{C} 57 \mathrm{BL} / 6 \mathrm{~J}$ mice did not show significant changes in these parameters after the same treatments (Table 3; insert here). The greater responsiveness of MRL/MpJ mice may be important for drug discovery, for genetic studies, and for understanding the neural mechanisms underlying the physiological and behavioral effects of chronic antidepressant treatments.

\section{Future Directions}

\section{Flow Cytometry and Neurogenesis}

Although the methodology described here can detect newly born cells, it is important that it ultimately be able to determine the phenotype of these cells. One of the advantages of flow cytometry is that multiple antigens can be investigated simultaneously. Once a cell is labeled with BrdU, other cellular markers can be used to give more specific information about the identity of a particular cell (i.e. neurons, glia, oligodendrocytes). In addition to identifying cell phenotypes, flow cytometry also has the potential to measure other markers of proliferation and proteins associated with the cell cycle. Antidepressant regulation of these proteins is an untapped area of research that could lead to novel mechanisms of drug regulation and possible new therapeutic targets.

\section{Antidepressants, Neuroplasticity, and Neurotransmitter Systems}

Although antidepressants drugs from diverse pharmacologic classes all elevate hippocampal neurogenesis, the precise neurotransmitters and receptors responsible for mediating this effect remain ill defined. For example, it is already known that the neurogenic effect of fluoxetine, but not imipramine, in the mouse is dependent on the 5- $\mathrm{HT}_{1 \mathrm{~A}}$ receptor (Santarelli et al., 2003). However, it is unclear when serotonin is needed, i.e. in the initial process or in the maintenance of the increased proliferative activity. Aside from the 5- $\mathrm{HT}_{1 \mathrm{~A}}$ receptor, little is known about the pharmacology behind the neurogenic properties of fluoxetine and other SSRIs. Moreover, little is known about the role of norepinephrine and its receptors in facilitating the up-regulation of neurogenesis by desipramine or other compounds that enhance noradrenergic signaling.

A similar theme holds true for the effects that antidepressants have on neurotrophins. Although it is well established that chronic treatment with pharmacologically distinct antidepressants upregulate BDNF levels (Balu et al., 2008), the primary receptors responsible for mediating these effects have yet to be fully characterized.

Elucidation of the receptors principally responsible for the effects of serotonergic and noradrenergic antidepressants on neuroplasticity would help to nominate classes of receptors as primary therapeutic targets. These receptors could also be therapeutic targets for other psychiatric and neurologic disorders that have neuroplasticity deficiency components.

The MRL/MpJ mouse can serve as a useful model for the neurogenic and behavioral responses following chronic antidepressant treatments because of their exaggerated responses to these treatments. Comparisons between responsive (MRL/MpJ) and nonresponsive (C57BL/6) strains of mice can identify the mechanisms underlying stress adaptation that are mobilized by chronic antidepressant treatments and lead to therapeutic effects when used in patients with depression. 


\section{Biography}

Dr. Darrick T. Balu won the APA Division 28 "Outstanding Dissertation Award" for 2009 on the basis of his research on the enhanced sensitivity of the MRL/MpJ mouse strain to the neuroplastic and behavioral effects of antidepressant treatments. He received the B.S. in Biology from Hofstra University, the M.S. in Pharmacology from St. John's University, and the Ph.D. in Pharmacological Sciences from the University of Pennsylvania. Dr. Balu's principal mentor during his Ph.D. training was Dr. Irwin Lucki. Dr. Balu is now a postdoctoral fellow at McLean Hospital, an affiliate of Harvard Medical School, in the laboratory of Psychiatric and Molecular Neuroscience under the guidance of Dr. Joseph T. Coyle.

\section{Acknowledgments}

This research was conducted by a National Center for Drug Discovery Group (NCDDG) in Mood Disorders established between the University of Pennsylvania and Wyeth Research and funded by USPHS Grant MH72832. First and foremost, I would like to thank my mentor Dr. Irwin Lucki. In addition to being a conceptual catalyst in many aspects of my dissertation, he was also extremely supportive of my own ideas and whenever I needed it, provided expert advice and words of encouragement. I would also like to thank my thesis committee members: Drs. Julie Blendy, Rita BaliceGordon, Seema Bhatnagar, and Brenda Porter. In addition, I am grateful for the advice and resources provided by our collaborators at Wyeth Research. The University of Pennsylvania Flow Cytometry Core Facility, especially Hank Pletcher, provided excellent technical assistance in the development of the BrdU assay. Finally, I would like to thank all the past and present members of the Lucki lab.

\section{References}

Baker KL, Daniels SB, Lennington JB, Lardaro T, Czap A, Notti RQ, et al. Neuroblast protuberances in the subventricular zone of the regenerative MRL/MpJ mouse. J Comp Neurol 2006;498(6):747-761. [PubMed: 16927265]

Balu DT, Hodes GE, Anderson BT, Lucki I. Enhanced sensitivity of the MRL/MpJ mouse to the neuroplastic and behavioral effects of chronic antidepressant treatments. Neuropsychopharmacology 2009;34(7):1764-1773. [PubMed: 19177066]

Balu DT, Hodes GE, Hill TE, Ho N, Rahman Z, Bender CN, et al. Flow cytometric analysis of BrdU incorporation as a high-throughput method for measuring adult neurogenesis in the mouse. J Pharmacol Toxicol Methods 2009;59(2):100-107. [PubMed: 19121403]

Balu DT, Hoshaw BA, Malberg JE, Rosenzweig-Lipson S, Schechter LE, Lucki I. Differential regulation of central BDNF protein levels by antidepressant and non-antidepressant drug treatments. Brain Res 2008;1211:37-43. [PubMed: 18433734]

Balu DT, Lucki I. Adult hippocampal neurogenesis: Regulation, functional implications, and contribution to disease pathology. Neurosci Biobehav Rev 2009;33(3):232-252. [PubMed: 18786562]

Beauquis J, Roig P, Homo-Delarche F, De Nicola A, Saravia F. Reduced hippocampal neurogenesis and number of hilar neurones in streptozotocin-induced diabetic mice: reversion by antidepressant treatment. Eur J Neurosci 2006;23(6):1539-1546. [PubMed: 16553617]

Bechtholt AJ, Valentino RJ, Lucki I. Overlapping and distinct brain regions associated with the anxiolytic effects of chlordiazepoxide and chronic fluoxetine. Neuropsychopharmacology 2008;33(9):21172130. [PubMed: 17987061]

Bilsland JG, Haldon C, Goddard J, Oliver K, Murray F, Wheeldon A, et al. A rapid method for the quantification of mouse hippocampal neurogenesis in vivo by flow cytometry. Validation with conventional and enhanced immunohistochemical methods. J Neurosci Methods 2006;157(1):54-63. [PubMed: 16876875]

Brocco M, Dekeyne A, Veiga S, Girardon S, Millan MJ. Induction of hyperlocomotion in mice exposed to a novel environment by inhibition of serotonin reuptake. A pharmacological characterization of diverse classes of antidepressant agents. Pharmacol Biochem Behav 2002;71(4):667-680. [PubMed: 11888558]

Clark LD, Clark RK, Heber-Katz E. A new murine model for mammalian wound repair and regeneration. Clin Immunol Immunopathol 1998;88(1):35-45. [PubMed: 9683548] 
Conti AC, Cryan JF, Dalvi A, Lucki I, Blendy JA. cAMP response element-binding protein is essential for the upregulation of brain-derived neurotrophic factor transcription, but not the behavioral or endocrine responses to antidepressant drugs. J Neurosci 2002;22(8):3262-3268. [PubMed: 11943827]

Crowley JJ, Blendy JA, Lucki I. Strain-dependent antidepressant-like effects of citalopram in the mouse tail suspension test. Psychopharmacology (Berl) 2005;183(2):257-264. [PubMed: 16220334]

Crowley JJ, Lucki I. Opportunities to discover genes regulating depression and antidepressant response from rodent behavioral genetics. Curr Pharm Des 2005;11(2):157-169. [PubMed: 15638756]

Cryan JF, Mombereau C, Vassout A. The tail suspension test as a model for assessing antidepressant activity: Review of pharmacological and genetic studies in mice. Neurosci Biobehav Rev 2005;29 (4-5):571-625. [PubMed: 15890404]

Dolbeare F. Bromodeoxyuridine: a diagnostic tool in biology and medicine, Part III. Proliferation in normal, injured and diseased tissue, growth factors, differentiation, DNA replication sites and in situ hybridization. Histochem J 1996;28(8):531-575. [PubMed: 8894660]

Dranovsky A, Hen R. Hippocampal neurogenesis: regulation by stress and antidepressants. Biol Psychiatry 2006;59(12):1136-1143. [PubMed: 16797263]

Dulawa SC, Hen R. Recent advances in animal models of chronic antidepressant effects: the noveltyinduced hypophagia test. Neurosci Biobehav Rev 2005;29(4-5):771-783. [PubMed: 15890403]

Duman RS, Monteggia LM. A neurotrophic model for stress-related mood disorders. Biol Psychiatry 2006;59(12):1116-1127. [PubMed: 16631126]

Ehninger D, Kempermann G. Neurogenesis in the adult hippocampus. Cell Tissue Res 2008;331(1):243250. [PubMed: 17938969]

Figurov A, Pozzo-Miller LD, Olafsson P, Wang T, Lu B. Regulation of synaptic responses to highfrequency stimulation and LTP by neurotrophins in the hippocampus. Nature 1996;381(6584):706709. [PubMed: 8649517]

Frazer A. Serotonergic and noradrenergic reuptake inhibitors: prediction of clinical effects from in vitro potencies. J Clin Psychiatry 2001;62:16-23. [PubMed: 11430614]

Gao HX, Campbell SR, Cui MH, Zong P, Hee-Hwang J, Gulinello M, et al. Depression is an early disease manifestation in lupus-prone MRL/lpr mice. J Neuroimmunol 2009;207(1-2):45-56. [PubMed: 19121871]

Gould E. How widespread is adult neurogenesis in mammals? Nat Rev Neurosci 2007;8(6):481-488. [PubMed: 17514200]

Gratzner HG. Monoclonal antibody to 5-bromo- and 5-iododeoxyuridine: A new reagent for detection of DNA replication. Science 1982;218(4571):474-475. [PubMed: 7123245]

Greer PL, Greenberg ME. From synapse to nucleus: calcium-dependent gene transcription in the control of synapse development and function. Neuron 2008;59(6):846-860. [PubMed: 18817726]

Gur TL, Conti AC, Holden J, Bechtholt AJ, Hill TE, Lucki I, et al. cAMP response element-binding protein deficiency allows for increased neurogenesis and a rapid onset of antidepressant response. $\mathrm{J}$ Neurosci 2007;27(29):7860-7868. [PubMed: 17634380]

Holick KA, Lee DC, Hen R, Dulawa SC. Behavioral Effects of Chronic Fluoxetine in BALB/cJ Mice Do Not Require Adult Hippocampal Neurogenesis or the Serotonin 1A Receptor. Neuropsychopharmacology. 2007

Jiang W, Zhang Y, Xiao L, Van Cleemput J, Ji SP, Bai G, et al. Cannabinoids promote embryonic and adult hippocampus neurogenesis and produce anxiolytic- and antidepressant-like effects. J Clin Invest 2005;115(11):3104-3116. [PubMed: 16224541]

Kim SH, Won SJ, Mao XO, Ledent C, Jin K, Greenberg DA. Role for neuronal nitric-oxide synthase in cannabinoid-induced neurogenesis. J Pharmacol Exp Ther 2006;319(1):150-154. [PubMed: 16831955]

Kulkarni VA, Jha S, Vaidya VA. Depletion of norepinephrine decreases the proliferation, but does not influence the survival and differentiation, of granule cell progenitors in the adult rat hippocampus. Eur J Neurosci 2002;16(10):2008-2012. [PubMed: 12453065]

Lagace DC, Fischer SJ, Eisch AJ. Gender and endogenous levels of estradiol do not influence adult hippocampal neurogenesis in mice. Hippocampus 2007;17(3):175-180. [PubMed: 17286277] 
Leferovich JM, Bedelbaeva K, Samulewicz S, Zhang XM, Zwas D, Lankford EB, et al. Heart regeneration in adult MRL mice. Proc Natl Acad Sci U S A 2001;98(17):9830-9835. [PubMed: 11493713]

Liu X, Gershenfeld HK. Genetic differences in the tail-suspension test and its relationship to imipramine response among 11 inbred strains of mice. Biol Psychiatry 2001;49(7):575-581. [PubMed: 11297714]

Manganas LN, Zhang X, Li Y, Hazel RD, Smith SD, Wagshul ME, et al. Magnetic resonance spectroscopy identifies neural progenitor cells in the live human brain. Science 2007;318(5852):980985. [PubMed: 17991865]

Merali Z, Levac C, Anisman H. Validation of a simple, ethologically relevant paradigm for assessing anxiety in mice. Biol Psychiatry 2003;54(5):552-565. [PubMed: 12946884]

Miller BH, Schultz LE, Gulati A, Cameron MD, Pletcher MT. Genetic regulation of behavioral and neuronal responses to fluoxetine. Neuropsychopharmacology 2008;33(6):1312-1322. [PubMed: 17609676]

Navailles S, Hof PR, Schmauss C. Antidepressant drug-induced stimulation of mouse hippocampal neurogenesis is age-dependent and altered by early life stress. J Comp Neurol 2008;509(4):372-381. [PubMed: 18512685]

Perrault G, Morel E, Zivkovic B, Sanger DJ. Activity of litoxetine and other serotonin uptake inhibitors in the tail suspension test in mice. Pharmacol Biochem Behav 1992;42(1):45-47. [PubMed: 1528946]

Ripoll N, David DJ, Dailly E, Hascoet M, Bourin M. Antidepressant-like effects in various mice strains in the tail suspension test. Behav Brain Res 2003;143(2):193-200. [PubMed: 12900045]

Sakic B, Szechtman H, Denburg JA. Neurobehavioral alterations in autoimmune mice. Neurosci Biobehav Rev 1997;21(3):327-340. [PubMed: 9168268]

Santarelli L, Saxe M, Gross C, Surget A, Battaglia F, Dulawa S, et al. Requirement of hippocampal neurogenesis for the behavioral effects of antidepressants. Science 2003;301(5634):805-809. [PubMed: 12907793]

Steru L, Chermat R, Thierry B, Mico JA, Lenegre A, Steru M, et al. The automated Tail Suspension Test: a computerized device which differentiates psychotropic drugs. Prog Neuropsychopharmacol Biol Psychiatry 1987;11(6):659-671. [PubMed: 2894041]

Steru L, Chermat R, Thierry B, Simon P. The tail suspension test: a new method for screening antidepressants in mice. Psychopharmacology (Berl) 1985;85(3):367-370. [PubMed: 3923523]

Teste JF, Martin I, Rinjard P. Electrotherapy in mice: dopaminergic and noradrenergic effects in the Tail Suspension Test. Fundam Clin Pharmacol 1990;4(1):39-47. [PubMed: 2341112]

Tsankova NM, Berton O, Renthal W, Kumar A, Neve RL, Nestler EJ. Sustained hippocampal chromatin regulation in a mouse model of depression and antidepressant action. Nat Neurosci 2006;9(4):519_ 525. [PubMed: 16501568]

Zhao C, Deng W, Gage FH. Mechanisms and functional implications of adult neurogenesis. Cell 2008;132 (4):645-660. [PubMed: 18295581] 


\section{Table 1}

Comparison of tissue serotonin content between MRL/MpJ and C57BL/6J mice across brain regions. The amount of analyte (5-HT, serotonin; 5-HIAA, 5-hydroxy indole acetic acid) from each region was quantified by HPLC and normalized to the wet weight of the tissue.

\begin{tabular}{lcc}
\hline & MRL/MpJ & C57BL/6J \\
\hline & $\begin{array}{c}\text { Tissue Content } \\
\text { (pg analyte / mg tissue) }\end{array}$ \\
Hippocampus & & \\
5-HT & $802 \pm 51 *$ & $641 \pm 24$ \\
5-HIAA & $388 \pm 24$ & $330 \pm 22$ \\
5-HT / 5-HIAA & 2.10 & 2.05 \\
Frontal Cortex & & \\
5-HT & $540 \pm 22 * *$ & $400 \pm 17$ \\
5-HIAA & $182 \pm 6 *$ & $115 \pm 8$ \\
5-HT / 5-HIAA & $3.00 *$ & 3.57 \\
Amygdala & & \\
5-HT & $948 \pm 34 * *$ & $744 \pm 32$ \\
5-HIAA & $192 \pm 11 * *$ & $124 \pm 6$ \\
5-HT / 5-HIAA & 5.10 & 5.84 \\
Brain Stem & & \\
5-HT & $654 \pm 31 *$ & $554 \pm 15$ \\
5-HIAA & $410 \pm 33 *$ & $324 \pm 15$ \\
5-HT / 5-HIAA & 1.65 & 1.73 \\
\hline
\end{tabular}

Asterisk indicates groups that differed significantly from each other $(* P<0.05, * * P<0.005)$ according to Student's $t$-test. 


\section{Table 2}

Comparison of behavioral responses to acute antidepressant treatments. MRL/MpJ (MRL) and C57BL/6J (B6) mice were injected with citalopram (CIT; $10,20 \mathrm{mg} / \mathrm{kg}$ ) or desipramine (DMI; 10, $20 \mathrm{mg} / \mathrm{kg}$ ) and tested 30 minutes after injection. (+: positive response, - negative response, 0 : non-significant response)

\begin{tabular}{ccccc}
\hline & \multicolumn{2}{c}{ Tail Suspension Test } & \multicolumn{2}{c}{ Locomotor Activity } \\
\hline Drug (mg /kg) & MRL & B6 & MRL & B6 \\
\hline CIT (10) & +++ & + & + & + \\
CIT (20) & ++++ & + & 0 & ++ \\
DMI (10) & ++ & + & 0 & - \\
DMI (20) & ++ & 0 & - & - \\
\hline
\end{tabular}




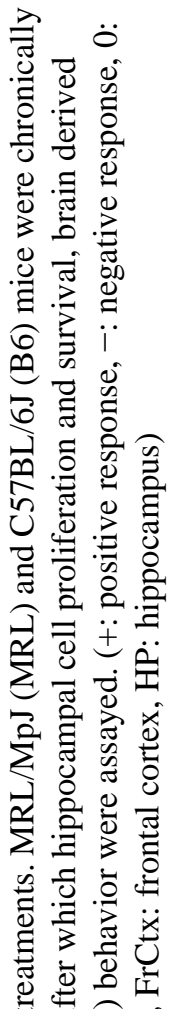

可进

$$
\text { .⿹丁口 }
$$

0

引

.

के

늘 휴

ติ

ปู

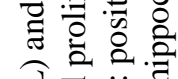

웧

¿ च

욜 छ

$<$ क

졸 즐 줄

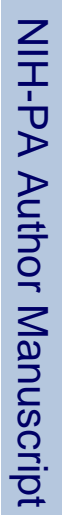

형 형

空

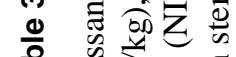

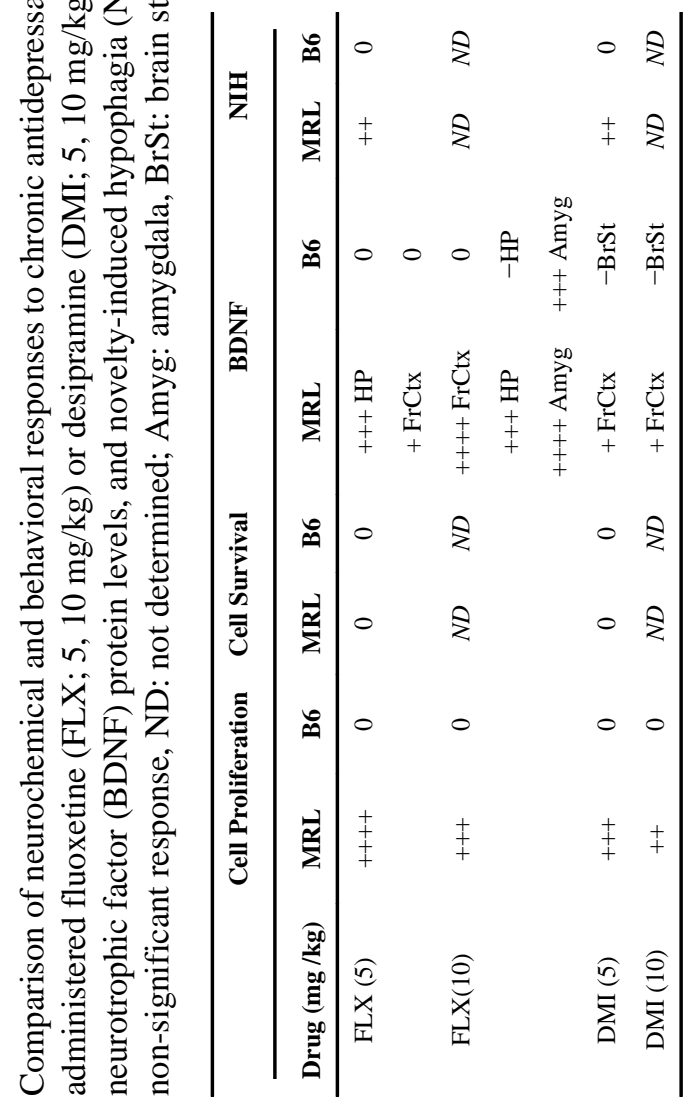

Exp Clin Psychopharmacol. Author manuscript; available in PMC 2010 May 13. 